\title{
Tiempo y Tiempos en "Deseos"
}

\author{
Christian Snoey Abadías* \\ Universitat Rovira i Virgili, Tarragona, Spain
}

\begin{abstract}
Time has always been a field full of experimental innovations during the 20th century, and Deseos, by Marina Mayoral, is not alien to that. This novel contains a double analysis of time: On one hand from a philosophical point of view, fiction gets divided on many occasions in two different parts: the chronological time of the clock and the psychological or lived time, which fits with the personal experience of time. On the other hand, from a technical perspective, the way time builds the structure of the text will be studied, and also the different kinds of flashbacks that allow characters' soliloquies. Finally, implicit and explicit time indicators that guide time's becoming will also be object of study.
\end{abstract}

Keywords: Marina Mayoral, Deseos, time, chronologic time, subjective time, flashback, simultaneity, explicit and implicit time indicators.

Resumen. El tiempo ha sido un campo prolijo en innovaciones experimentales en la narrativa del siglo XX, y Deseos, de Marina Mayoral, no es ajena a ellas. Esta novela se presta a un doble análisis temporal: Por un lado, desde una perspectiva filosófica, la ficción se divide en numerosas ocasiones en dos planos o estratos: el tiempo cronológico o del reloj y el psicológico o vivido, que se correspondería con la experiencia subjetiva del tiempo. Por otro lado, desde una perspectiva técnica, se

\footnotetext{
* Author's address:

Departament de Filologies Romàniques

Universitat Rovira i Virgili

Av. Catalunya 35, 43002 Tarragona, Spain

E-mail christian_snoey_89@hotmail.com
} 
estudiará cómo el tiempo construye la estructura textual, se analizarán los distintos tipos de analepsis que articulan los soliloquios de los personajes y, finalmente, los indicadores temporales explícitos e implícitos como marcas que encauzan el devenir temporal.

Palabras clave: Marina Mayoral, Deseos, tiempo, tiempo cronológico, tiempo subjetivo, analepsis, simultaneidad, indicadores temporales explícitos e implícitos.

\section{Introducción}

Pocas páginas hace falta pasar para que sobrevengan los interrogantes: ¿por qué distintas horas del día titulan los capítulos?, ¿por qué el tiempo cobra tanta relevancia?, ¿por qué desde el principio se intuye que no hay un tiempo homogéneo, sino plural? Esta clase de preguntas no son baladíes ni gratuitas, puesto que Deseos, de Marina Mayoral, destaca, entre otros aspectos, por la manera en que juega con el tiempo. La acción principal de la novela se condensa en un día, desde las $06.30 \mathrm{~h}$ de la mañana hasta la $01.00 \mathrm{~h}$ del día siguiente; concretamente, esa fecha es el 12 de octubre de 1982. Durante este largo día, el tedio inherente a Brétema y del que tanto se lamentan sus personajes se trastoca por un entramado de acontecimientos: la violación brutal de una joven, la extraña muerte de Juanma y, finalmente, un accidente de tráfico. Sin embargo, la trama de la novela se extiende más allá de estas fronteras, pues en este marco se imponen las diferentes vidas de los múltiples personajes: su pasado, sus deseos, sus vaivenes; en definitiva, aquellos hitos insoslayables de su biografía.

Concienciada la crítica del carácter constitutivamente temporal de la novela, han sido varios los enfoques adoptados para desentrañar esta íntima relación. Dibujando brevemente el estado de la cuestión, Gérard Genette (1989), con su conocido ensayo Figuras III, asentó las bases del estudio narratológico del tiempo mediante un método esencialmente textual o retórico, partiendo de la distinción entre el tiempo de la historia -entendido como el desarrollo lógico y causal de los sucesos- y el tiempo del relato -es decir, la disposición artística de esos sucesos. Asumiendo la ausencia de correlación entre ambos, su planteamiento deviene en tres fundamentos: el orden temporal, la duración y la frecuencia. El primero de ellos es el que interesa para este análisis, dado que el orden temporal se basa en las anacronías, divididas en analepsis y prolepsis, derivadas de la falta de unicidad entre el orden lógico de la historia y la manera en que ese orden se altera en el relato, y 
en Deseos los personajes recuperan con profusión el pasado para explicar y explicarse. La otra obra insoslayable en lo que respecta a la temporalidad de la ficción es Tiempo y narración de Paul Ricoeur. El segundo tomo de su estudio supone una aguda revisión crítica del estructuralismo, concretamente del modelo genettiano basado en la distinción entre enunciación y enunciado. Asentándose en la concepción de que la ficción es creación de un mundo, como apunta Pozuelo Yvancos (2004), Ricoeur reivindica aquello que se le escapa al análisis narratológico: la vivencia subjetiva del tiempo por parte de los personajes:

La racionalidad, explicable y loable para los fines que persigue..., del sistema genettiano, su central estructuralidad tiene empero un punto de incomprensión al que P. Ricoeur se resiste: la incapacidad para dar cuenta del tiempo como experiencia, del tiempo subjetivo, cuyo lugar privilegiado es la durée, el tiempo, el sentimiento del tiempo (Pozuelo Yvancos 2004: 101).

A los escritores no les ha pasado inadvertida la cualidad temporal de la conciencia en el momento de penetrar en ella. Julio Cortázar, un referente en lo que atañe a la indagación de la temporalidad ficcional, inicia el cuento "La autopista del sur", perteneciente a Todos los fuegos el fuego, de la siguiente manera: "Cualquiera podía mirar su reloj pero era como si ese tiempo atado a la muñeca derecha o el bip bip de la radio midieran otra cosa" (Cortázar 2012: 11). Desde ese momento se explicita la disolución del tiempo cronológico, medible por sucesivos tictacs, para que los personajes se abandonen a la experimentación psicológica del tiempo (Pozuelo Yvancos 2004). En Deseos también se construye esa vivencia subjetiva del tiempo, aunque aquí corre paralela a la sucesiva cronología exterior, por lo que en la primera sección, titulada homónimamente Tiempo y tiempos, se recorrerán sucintamente algunas lecciones filosóficas, deteniéndose en particular en las de Henri Bergson, pues se pretende desembocar en el análisis de la durée en esta novela. Además, dado que la focalización se evidencia íntimamente ligada a la temporalidad, las peculiaridades de las voces narrativas se tratarán independientemente para, no solo desentrañar la sobredicha relación, sino también su diálogo con las indagaciones del pretérito siglo. No obstante, el tiempo es propicio a otras perspectivas de análisis además de la existencial, pues también cumple una función pragmática: mediante la trabazón temporal se estructura composicionalmente la novela; por tanto, se le atribuye un significado cohesionador, 
que se pormenorizará junto con un análisis de las retrospecciones siguiendo el modelo de Genette, de cuyo método se toma solamente aquello pertinente y que afecta a los elementos con mayor relevancia textual; es decir, el orden temporal -concretamente las analepsis. Por último, se tratará acerca de las modalidades de indicaciones temporales que jalonan el avance de la novela, pues el edificio narrativo, de corredores diáfanamente planeados, se construye mediante alusiones, diálogos, reflexiones y referencias directas que responden al fin de crear la geografía temporal en la mente del lector.

\section{Tiempo y Tiempos}

Las reflexiones sobre el tiempo surgen tempranamente en el pensamiento del ser humano. En nuestra tradición destacan las que deja escritas con íntimo título san Agustín de Hipona en el libro XI de sus Confesiones: después de departir con minuciosidad acerca de la naturaleza del presente, del pasado y del futuro concluye que "És en tu, esperit meu, que mesuro el temps" (Hipona 2007: 350). Esta aseveración implica que la existencia y la continuidad del tiempo residen en el interior, desde donde se pueden abarcar el pasado y el futuro -procedimiento que el autor denomina distentioanimi- (Ricoeur 1996).

En la filosofía moderna, resurge con fuerza la preocupación por esta intrincada dimensión del ser; por ejemplo, Kant considera el tiempo, junto con el espacio, como uno de los constituyentes de la estética trascendental, con ostensiva autonomía de los objetos: "El Tiempo es la forma del sentido interno, es decir, de la intuición de nosotros mismos y de nuestro estado interior. El Tiempo no puede ser determinación alguna de los fenómenos externos, no pertenece ni a la figura, situación, etc." (Kant 1976: 186). Por otro lado, las teorías que han arraigado con mayor éxito en la narrativa del siglo XX son las de Henri Bergson -recuérdese el ejemplo paradigmático de En busca del tiempo perdido de Proust o en el ámbito de la poesía española su rastro filosófico en Antonio Machado. En el Ensayo sobre los datos inmediatos de la conciencia es donde aparece por vez primera la antítesis esencial de su pensamiento metafísico entre el tiempo exterior, concebido espacial y físicamente por la ciencia y cuya medida reside en las agujas del reloj, por lo que se entiende como una falsificación, y el tiempo psíquico, conceptualizado en durée o tiempo vivido, que se aviene con la representación temporal en la conciencia. El fin ontológico y último de la distinción sostenida en este ensayo 
es la exaltación de la libertad humana atenazada, en su cosmovisión, por el determinismo científico:

distinguimos dos formas de la multiplicidad, dos apreciaciones muy diferentes de la duración, dos aspectos de la vida consciente. Por debajo de la duración homogénea, símbolo extensivo de la auténtica duración, una psicología atenta distingue una duración cuyos momentos heterogéneos se penetran; por debajo de multiplicidad numérica de los estados conscientes, una multiplicidad cualitativa; por debajo del yo en los estados bien definidos, un yo en el que la sucesión implica fusión y organización (Bergson 2012: 17).

Por último, Martin Heidegger, en Ser y tiempo, se plantea una cuestión filosófica de orden esencial, es decir, qué es ser, y para comprenderlo recurre al tiempo como fundamento de su interpretación: "El tiempo deberá ser sacado a la luz y deberá ser concebido genuinamente como el horizonte de toda comprensión del ser y de todo modo de interpretarlo" (Heidegger 2012: 38).

Extrapolando las teorías de Bergson a la narrativa y atendiendo especialmente a la experiencia subjetiva del tiempo, su dicotomía temporal se aprecia con claridad en Deseos: pueden establecerse en la novela dos estratos diferenciados, pero a la vez imbricados e interrelacionados. Por un lado, se halla el tiempo exterior, objetivo o del reloj, que se corresponde con el de la trama; es decir, las horas de ese día en que transcurre la acción, y viene marcado por el narrador en tercera persona a través sus indicaciones temporales. Por otro lado, surge el tiempo interior o psicológico, el de la conciencia, que se corresponde con los personajes, puesto que en numerosas ocasiones entablan un soliloquio consigo mismos. Este tiempo está ligado a sus apreciaciones subjetivas, pero sobre todo al pasado, a sus recuerdos, a sus vivencias y especialmente a sus deseos, unas veces satisfechos, otras frustrados, en ocasiones inconfesables y hasta vergonzantes. Por tanto, los personajes, como instancias narrativas, son voces y tiempos, pues no solo se insertan en el tiempo de ese día que actúa como marco globalizador, sino que cada uno transita a su duración interior en sus procesos introspectivos. Además, de la combinación de ambos tiempos surge la sucesión temporal: se aprecia un constante fluir que se desplaza desde el exterior -narrador en tercera persona- al interior -soliloquios-; así, mientras los personajes dialogan consigo mismos el tiempo va corriendo. Para ilustrar esta interpretación de la novela dividida en estratos 
valga este fragmento seleccionado, entre muchos otros que se podrían haber tomado:

Etelvina está tumbada en la cama a oscuras, con las piernas flexionadas y las manos bajo la nuca. Suenan en el reloj de la catedral cuatro cuartos y doce campanadas. Suspira. ¡Al final has acabado! Ha sido un largo día, pero al fin has acabado, iqué satisfacción!, lástima de tantas desgracias, apenas has podido celebrarlo. Con Alberto sí, se alegró tanto, pero tuviste que contarle lo de Juanma y los problemas de la doctora, y la violación de la chica, y la persecución de la Guardia Civil (Mayoral 2011: 330).

Por tanto, el primer párrafo de este ejemplo corresponde a la voz del narrador en tercera persona, que se inserta en un tiempo exterior o físico, concretamente en el presente, del cual no se puede desplazar por su ausencia de intromisión en la mente de los personajes; así, se limita a bosquejar una descripción de la postura y actitudes de Etelvina y a ofrecer una breve cronografía en forma de indicación temporal explícita. En el segundo párrafo, en cambio, sin aviso ni enlace, se penetra en otro plano distinto, en otro tiempo: el psicológico o vivido, que solo puede sentirse en su mente y que emana de sus pensamientos, entre los cuales deambulan enérgicamente ese largo día que subjetivamente percibe, el gozo de haber finalizado su libro, una conversación y los diversos sucesos que conforman la trama de la novela. Resulta significativo, en la línea de la durée bergsoniana, que el primer capítulo se cierre con una reflexión de Dictino sobre el tiempo: después de oír las campanas de la catedral señala que, por estar tan concentrado en su trabajo y en sus pensamientos, el tiempo ha pasado tan rápido que no sabe determinar qué hora es. Por tanto, desde el primer capítulo se indica ya la percepción subjetiva del tiempo vivido:

¿Tres cuartos para las ocho o para las nueve? Cuando haces talla se te van las horas sin sentir, y no te gusta llevar reloj, no te gusta contar las horas, de eso ya se encarga Amalia (Mayoral 2011: 24).

\section{Voces y Tiempos}

El tiempo, pues, va ligado a las voces, ya que estas lo organizan. La primera instancia narrativa que aparece es el narrador en tercera persona, que ostenta 
la peculiaridad de no intervenir: solamente se limita a dar indicaciones temporales, espaciales y acerca de gestos y actitudes de los personajes. Su grado de alejamiento es tal que incluso en ocasiones no asevera, sino que insinúa, debido a que no se introduce en la mente de los personajes, por lo se encuentran citas como esta: "Parece nerviosa" (Mayoral 2011: 269-270). En segundo lugar, se hallan los diálogos que entablan consigo mismos los personajes, a veces en segunda persona, técnica que puede considerarse como una de las innovaciones introducidas en la narrativa del siglo XX respecto a la experimentación con el punto de vista; por ejemplo: "Vamos, Etelvina de Silva, resumamos la situación" (Mayoral 2011: 108) o "Si te das prisa estarás en el comedor antes de que terminen" (Mayoral 2011: 111). Mediante estos soliloquios se consigue que los personajes profundicen en sí mismos, que ahonden en el enigma de su vida. Así, se crea un ir y venir de temas que se repiten, se reformulan y se amplían con el fin de reproducir el diálogo con uno mismo y, en cierto sentido, el fluir de la mente, sin llegar a ser monólogo interior o stream of consciousness. Los temas que emanan de sus reflexiones son variados, pues no solo retroceden en el tiempo para analizar distintos sucesos de su vida, sino que también ofrecen indicaciones temporales $\mathrm{u}$ opinan sobre acontecimientos y personajes de Brétema. Además, el uso del narrador en segunda persona resulta un medio a través del cual se deja ver de forma patente este tiempo psicológico o vivido:

El tú tiene un amplio efecto temporal sobre el relato, ya que a la vez que rescata el pasado sirve para poner de relieve con gran expresividad la conciencia del presente. Y junto a esto, a niveles simbólicos que quizá no queridos por los mismos autores, pero en mayor o menor grado innegables, supone también un refugiarse el personaje en sí mismo, el establecimiento de un diálogo entre el yo y ese alter ego dramático (Sanz Villanueva 1976: 260).

En tercer lugar, se encuentran capítulos o escenas formados por diálogos entre personajes; en este sentido destacan las páginas dedicadas a Etelvina y a Constanza. Los capítulos de la primera son especialmente complejos desde el punto de vista técnico, pues remiten al pasado mediante conservaciones entre ella y Germán grabadas en cintas que ella reproduce; por tanto, se emplea un tipo de analepsis original e inusual. Constanza, por otro lado, acude durante ese día en dos ocasiones al cementerio para hablar con su difunto esposo, Pedro, y con el también fallecido Hermes, quien personifica en realidad su 
deseo; estos diálogos resultan intrigantes, pero a la vez no extraños en quien religiosamente acude al camposanto, pues ella se dirige a ellos y fabula sus respuestas, o acaso mejor dicho Constanza recibe contestación, pero no el lector, quien infiere o aventura la posible réplica, por lo que también ostenta un papel activo en la novela reconstruyendo las ausencias; por ejemplo: "No, no lo estoy mirando, puede que se me vayan los ojos alguna vez, pero no estoy con Hermes, estoy contigo" (Mayoral 2011: 195).

Además del tiempo como prioridad experimental, otra piedra de toque de la narrativa del siglo pasado, que se extiende hasta la de los inicios del siglo XXI, es la focalización, dirigida a desmitificar la visión endiosada del narrador omnisciente decimonónico. En concreto, las tentativas se han centrado en la experimentación con el narrador en segunda persona sobredicho y con la perspectiva multivisional o caleidoscópica (Sanz Villanueva 1976). Esta última técnica consiste en la narración de un mismo acontecimiento desde distintos puntos de vista, de tal manera que se consigue desplazar de la ficción el enfoque totalitario de un solo narrador que presenta una única visión de la realidad, pues así se despliegan una serie de interpretaciones equivalentes a la cantidad de personajes. Por tanto, se infiere que este procedimiento implica la multiplicación material de un mismo tiempo que se repite en función de los personajes partícipes, como sucede en Deseos. El fin último de esta postura multivisional responde a la intención de presentar una ilusión de objetividad: por ello, el narrador en tercera persona se limita a retratar la realidad, sin intervenir en ella; o mejor dicho, solamente apunta breves bosquejos pictóricos o fogonazos de ella, para que sean los personajes quienes la interpreten mediante sus introspecciones psicológicas. Y se considera como ilusión de objetividad a causa de la condición subjetiva inherente al autor que ejecuta la novela; sin embargo, desde esa visión personal de la realidad se pretende alcanzar la objetividad, entendida como ámbito verosímil para el lector. Sin duda, como se ha señalado, esta elección del punto de vista repercute sobre la organización temporal, puesto que, a causa de que el narrador en tercera persona se caracteriza por su ausencia de interpretación de la realidad, su ámbito se limita al presente; son los personajes, en cambio, quienes pueden transitar tanto por el presente como proyectarse hacia el pasado o el futuro. 


\section{Estructura Temporal}

En sus oscilantes soliloquios, el personaje de Etelvina ${ }^{2}$, a quien se le sorprende en el proceso de creación literaria, por su condición de escritora, no solo pincela fragmentariamente su vida, sino que también desliza reflexiones metaliterarias y referencias o alusiones a otros escritores como Unamuno, Cernuda o Emilia Pardo Bazán. Incluso se halla un diálogo entre la obra que Etelvina está escribiendo, la Historia de La Braña, y Deseos, pues en un momento dado este personaje revela la manera en que entiende la composición estructural de una novela, y ese molde resulta ser el mismo que sigue Deseos: "Escribe una cosa detrás de la otra, clarito y seguido; organízalo por fechas y por personas. En la Braña ha habido siempre mucha gente" (Mayoral 2011: 97) le recomienda su tía abuela Ana Luz. Así, en estas palabras especulares se descubre reflejada la novela de Marina Mayoral, por lo que los límites entre realidad y ficción se difuminan con este guiño. Puede hablarse, por tanto, de esta reflexión como un ejemplo de mise en abîme, concepto acuñado por André Gide para designar ese fenómeno de reduplicación dentro de la novela de la totalidad o lo esencial de la obra, como puede suceder, ilustrativamente, con las muñecas rusas.

Novelistas como Balzac, Flaubert o Tolstoi muestran la evolución de los personajes a lo largo de toda una vida; en ocasiones incluso abarcan generaciones. La acción de Deseos, en cambio, transcurre durante un día. A partir del siglo XX la novela comienza a recibir nuevos tratamientos, entre los cuales destaca la reducción temporal (Villanueva 1977); es decir, el novelista no acomete la empresa de abarcar toda una vida, sino que la acción transcurre en pocas horas o en un día, como en el caso de la obra de Marina Mayoral. Mediante este procedimiento se consigue que el tiempo adquiera mayor preeminencia y, especialmente, que se perciba su duración casi palpablemente. Sin embargo, los derroteros experimentales de la anterior centuria no se han centrado exclusivamente en el acortamiento temporal, sino que se han diversificado en distintas tentativas con el fin de captar una de las dimensiones de la existencia que progresivamente se ha ido revelando ineludible: la manera en que el humano siente o percibe el tiempo:

${ }^{2}$ Etelvina de Silva es la narradora de otra novela de Marina Mayoral, ¿Quién mató a Inmaculada de Silva? Esta es otra de las peculiaridades de Deseos: el retorno de personajes que habían aparecido en obras anteriores de la autora, lo que crea un universo propio e íntimo. 
Los motivos de la relevante presencia del tiempo en la narrativa moderna son varios: las raíces de la durée bergsoniana como se observa en Proust; la función de la memoria que necesariamente se desarrolla en el tiempo, como en Faulkner; la presencia del cine, para el que no hay más que un tiempo posible, el presente, como ha tratado de demostrarlo Robbe-Grillet; la teórica coincidencia del tiempo de la lectura y la duración externa de la acción, como se ve en Joyce, Böll...; amén de la desfiguración temporal en el realismo mágico o en la moderna literatura sudamericana (Sanz Villanueva 1970: 251).

No obstante, pese a que se reduzca el tiempo de la trama, este se amplía transitando hacia el pasado mediante reiteradas analepsis, cuyas consecuencias devienen en la ruptura de la linealidad y la imbricación de los distintos tiempos. Debido a esta reducción se propicia un ritmo narrativo lento, acentuado, además, en este caso, por el insistente sonido de fondo de las campanas del reloj de la catedral.

El principal problema que plantea una novela construida a partir de tantos personajes es el de su unidad; para solventarlo se acude a una serie de procedimientos. El elemento fundamental que otorga coherencia es el tiempo, puesto que la acción queda enmarcada entre las 6.30 h y la 01.00 h del día siguiente. Otro factor cohesionador es el espacio, Brétema, pues en él suceden unos acontecimientos de los que los personajes participan, ya sea como afectados, como observadores o solo como transmisores. Además, este pueblo infunde en el carácter de los personajes un halo idiosincrásico, pues es un paisaje ceniciento, lluvioso y poblado por la niebla -Brétema en gallego significa 'niebla'. También se consigue unidad gracias a la simultaneidad; el ejemplo más destacado es cuando, en el inicio de la novela, a las 6.30 h, Dictino, Consuelo, Blanquita, Amalia, Miguel y Etelvina ven a Héctor Monterroso descendiendo la calle y se interrogan acerca de dónde y con quién habrá pasado la noche. La simultaneidad de la acción es una de las características más destacadas de Deseos, que se resuelve enmarcando a los múltiples personajes en las distintas horas, pues, como constata Borges en El Aleph, el lenguaje es sucesivo: "Lo que vieron mis ojos fue simultáneo: lo que transcribiré, sucesivo, porque el lenguaje lo es" (Borges 2003: 192). Pese a ello, el lector es conocedor de que lo que le sucede a la vez, pero visto desde otra perspectiva. $\mathrm{Y}$, finalmente, otro factor fundamental que cohesiona la novela temáticamente son, sin duda, los deseos, que actúan a modo de leitmotiv. 
Como se ha señalado, el tiempo cumple una función cohesionadora: el sonido de las campanas marca el inexorable paso de las horas; sin embargo, esta no es su única función, pues atesoran un valor simbólico. Por un lado, recuerdan el irreparable paso del tiempo y, por otro, se asocian con la muerte. Concretamente, mueren dos personajes, Juanma y uno de los hombres que violan a la joven. En Deseos resuena constantemente el doblar de las campanas: el tiempo pesa, es palpable, persistente, no cae en el olvido.

La novela sucede sobre todo en la mente de los personajes, enraizada en el tiempo interior, psicológico, subjetivo; por ello, se remite constantemente al pasado gracias al poder actualizador de la consciencia, pues en él se encuentran el origen de sus deseos y aquello que, en definitiva, les constituye. Así, el relato se fundamenta en la técnica de la analepsis o retrospección, que se presenta bajo distintas formas. Según el modelo presentado por Gérard Genette (1989), las analepsis pueden ser externas, internas y mixtas: las tres se hallan en Deseos. Las del primer tipo son aquellas cuyo origen se encuentra antes del inicio de la novela: los diálogos de los personajes consigo mismos se construyen principalmente mediante esta modalidad, puesto que, en primer lugar, la obra dura solo un día y, en segundo lugar, porque todos los personajes se remontan a su pasado para analizarse, y confesarse, reconocerse y cuestionarse las causas de su estado actual, consecuencia de sus deseos. Por tanto, los ejemplos son numerosos: Consuelo recuerda su juventud, pues en esa época nació su hondo amor por Juanma y también su desgracia actual, ya que la culpabilidad de haber anhelado un accidente de este para, así, cuidarlo asola su vida. Amalia recuerda que, movida por su ansia de ser madre, sedujo a Dictino superando sus dificultades con el sexo. Constanza, a su vez, revive en el cementerio el recuerdo -y de hecho vive de él- de sus dos grandes amores y reconstruye su vida desde su infancia. Destacan por su complejidad las retrospecciones de los capítulos de Etelvina, puesto que se crea un sutil juego de intertextualidad fruto de la creación de un universo literario hogareño plagado de connotaciones e hilos que el lector ha de enlazar. Etelvina alude a que con dieciséis años investigó la sospechosa muerte de Inmaculada de Silva, una antepasada suya, y se pregunta: “Dónde se quedaron las notas que escribiste entonces? Te vendría bien disponer de aquel diario" (Mayoral 2011: 98). Concretamente esta parte de su pasado se encuentra en otra novela de Marina Mayoral: ¿Quién mató a Inmaculada de Silva? En su intervención de las $14.00 \mathrm{~h}$ aparece una parte oscura de su vida que ella prefiere silenciar de la Historia de La Braña, sus amores con Toño, que se narran en La única libertad, donde también aparecen las tías abuelas. Finalmente, en los soliloquios 
de otros personajes como Amalia o Blanquita también aparecen referencias a las difuntas y antitéticas Helena y Blanca, pero su presencia cobra mayor relevancia en los capítulos de Etelvina, pues, además, está concluyendo la Historia de Blanca y Helena; sin embargo, su historia se cuenta en Recóndita armonía, por lo que la obra ficticia de Etelvina la reabre, completa y amplía desde otra perspectiva. Este juego de intertextualidad se explicita mediante notas al pie de página que remiten a las ediciones publicadas. De Etelvina, además de hallar metaliteratura, se puede inferir una de las posturas del escritor frente a la literatura, pues ella busca respuestas para sus preocupaciones o incertidumbres en las historias de los demás.

El segundo tipo de analepsis corresponde a las internas, es de decir, a aquellas cuyo alcance se extiende dentro del relato base. Son menos abundantes, pero no por ello menos importantes, puesto que esta clase de retrospección se emplea para narrar los acontecimientos principales de la trama. En el centro del día, se pasa de las tres de la tarde -"Suenan en el reloj de la catedral las tres de la tarde" (Mayoral 2011: 246) - a las seis; sin embargo, ese espacio temporal se llena con una analepsis interna que surge de una conversación entre Miguel y su madre: "A las cuatro y media, después del esquilón que llama al coro en la catedral tocaron a muerto" (Mayoral 2011: 258). Poco después se aclara que quien ha muerto, como se había dejado entrever con anterioridad, es el marido de Consuelo; por tanto, esta retrospección explica un hecho crucial de la trama. Otro ejemplo semejante se da en el capítulo dedicado a Blanquita a las 20.00 h: en él, su amiga Inés le cuenta, empleando una analepsis, que Miro lleva a la Guardia Civil al lugar de la violación; casualmente los presuntos criminales se acercaron también allí, por lo que se inició una persecución que finaliza cuando el coche de los violadores se sale de la carretera y Adolfo, el conductor, muere aplastado.

El último tipo de analepsis son las mixtas: se inician antes del tiempo del relato base, pero finalizan en él. En Deseos esta formulación se emplea para aludir a hechos acaecidos la noche anterior y cuyo término se halla en el día de la acción principal. Se da especialmente en los capítulos de Miguel, pues en el que corresponde a las 06.30 h se narra todo el episodio de la violación de la joven, desde su inicio hasta que Miro la trae junto a su hermana pequeña al ambulatorio:

Perdone que la llame a estas horas. ¿La he despertado?... Edelmiro, el de los transportes, ha traído a una chica, la encontró en A Revolta, 
entre zarzas, la han violado, casi seguro, tiene rota la ropa, y le han dado una paliza (Mayoral 2011: 83).

El uso de los tiempos verbales es, también, destacado, ya que varía en función de las voces narrativas. Los personajes, al contario del narrador en tercera persona, gozan de mayor libertad, puesto que emplean los tiempos de pretérito para referirse a su pasado; no obstante, en sus soliloquios también prolifera el presente en distintas modalidades. La más destacada de ellas es cuando los personajes emplean este tiempo verbal para narrar un acontecimiento pasado, pues relatándolo en presente cobra viveza y cercanía; por ejemplo, en el primer capítulo de Dictino:

Doña Constanza se rió de esa manera suya, echa la cabeza hacia atrás y le palpita el cuello que parece marfil entre los rizos rojos y se le ven todos los dientes tan blancos y brillantes (Mayoral 2011: 15).

\section{Indicadores Temporales Explícitos e Implícitos}

El tiempo adquiere una fuerte presencia a lo largo de toda la novela; constantemente, tanto la voz del narrador como los personajes insisten en él. Así, se contribuye a la veracidad del relato, pues las indicaciones son tan precisas que permiten crear un entramado casi visible. Son diversas las formas en que se presenta el paso del tiempo en la acción, por lo que se puede distinguir entre referencias temporales explícitas e implícitas. Las primeras aluden al tiempo indicado mediante el reloj: sin duda, este tipo de indicadores son estructuradores de la obra, ya que las horas titulan los capítulos; por tanto su papel de guía es ineludible. Además, se indica constantemente la hora mediante las campanadas del reloj, por lo que tanto los personajes como el lector son conscientes del paso del tiempo y de su peso. Así, los ejemplos proliferan: "Suenan en el reloj de la catedral cuatro cuartos y doce campanadas" (Mayoral 2011: 330) о:

Se oye el crujido de la puerta del taller y enseguida dos campanas de los cuartos en el reloj de la catedral. [...] Vuelve la cabeza para mirar el reloj de la mesilla: las seis y media (Mayoral 2011: 42). 
Los indicadores temporales implícitos adquieren formas más variadas y ricas en matices, puesto que en esta novela se hallan relacionados con la modificación del paisaje y con costumbres sociales; además, el contexto de un pueblo permite juegos de esta índole. Por ello, se describe el amanecer en numerosas ocasiones en los primeros capítulos correspondientes a las $6.30 \mathrm{~h}$ : "una luz tenue, rosada, ilumina el cielo por encima del monte" (Mayoral 2011: 11) o "En las ventanas de las casas de enfrente se refleja un resplandor rosado. Está ya amaneciendo" (Mayoral 2011: 25). Constanza acude por segunda vez en ese día al cementerio a las seis de la tarde, por lo que en ese capítulo se encuentran indicaciones del atardecer: "La luz del ocaso hace más intenso el rojo de los mechones que rodean su cara" (Mayoral 2011: 276) o "Entre las nubes de suave color malva se ve un lucero" (Mayoral 2011: 282). Finalmente, en los capítulos correspondientes a las $00.00 \mathrm{~h}$, se alude a la luz proveniente de las casas vecinas para resaltar, por contraste, la oscuridad de la calle: "A través de los cristales del amplio ventanal de dos hojas se ven las ventanas de la casa de enfrente, iluminadas" (Mayoral 2011: 285). El juego entre luz y oscuridad es otro de los indicadores implícitos que abundan en Deseos, debido a que en el inicio y en el final la luz de las farolas contribuye a crear el marco temporal: "Limpia con la mano el vidrio empañado y mira hacia afuera: el cielo es aún negro y los faroles están encendidos" (Mayoral 2011: 25).

Se ha señalado que las campanadas de la catedral forman parte de los indicadores explícitos; sin embargo, pese a indicar la hora con precisión, en cierto sentido también participan de los implícitos, ya que son costumbres sociales que solo perduran en los pueblos, como el imaginario Brétema. Dentro de estos hábitos culturales destaca el sonido de las campanas tocando a maitines en el segmento final de la novela correspondiente a las 00.00 h; es decir, la llamada a la primera de las horas canónicas que se reza antes de que amanezca. Por tanto, suenan a la $01.00 \mathrm{~h}$ de la madrugada. Al final de Deseos, el sonido de estas campanas, sumadas a las de la catedral, se escucha con insistencia, a causa de la repetición en distintos capítulos originada por la simultaneidad, para enfatizar la idea de que se inicia un nuevo día y, por tanto, que el desastroso día anterior ha quedado atrás. Por ello, la novela concluye de esta manera, dejando su sonido perpetuándose en los oídos del lector:

En el reloj de la catedral se oyen cuatro cuartos y una hora. La campana del convento de las monjas enclaustradas toca a maitines. Comienza un nuevo día (Mayoral 2011: 352). 
Cabe destacar que las indicaciones temporales se disponen principalmente en el inicio de los capítulos para crear el marco en el imaginario del lector, y al final, donde se suelen destacar las campanadas, para ganar en contundencia y dejar resonando en los oídos el peso de su eco.

\section{Conclusiones}

Acercándose a las implicaciones del concepto de ficción enraizado en la explicación del humano, Wolfgang Iser, en el inicio de su ensayo "La ficcionalización: dimensión antropológica de las ficciones literarias", asienta la siguiente aproximación a la obra literaria: "la mentira sobrepasa la verdad y la obra literaria sobrepasa el mundo real que incorpora" (Iser 1997: 43). Sin embargo, la ficcionalización va más allá: no solo sobrepasa esa realidad referente, sino que supone la creación del mundo, según el entendimiento de Ricoeur (1996). Y en esa invención, que ya no es espejo, sino más bien indagación en la existencia, se insertan personajes dotados de conciencia, de vida psicológica; entonces el lector asiste al prodigio de encaramarse a los laberintos verticales de los pensamientos, vaivenes emocionales y deseos pretéritos y de huella presente de esas creaciones textuales. Por tanto, desde el momento en que se inventa esa conciencia, también se la dota de la experiencia subjetiva del tiempo. Así, Deseos se estratifica en dos realidades imbricadas: el tiempo subjetivo en el que se desliza sutilmente el personaje -y por tanto el lector- en el momento en que toma la palabra mediante sus soliloquios en contraste con el presente cronológico de la historia. Ese presente, determinado por el narrador en tercera persona, es unidireccional, pues solo se proyecta hacia el futuro, que son las horas que van avanzando hasta que doblan las campanas que señalan el nuevo día; el tiempo subjetivo, en cambio, es plástico, maleable, pues se extiende hacia el pasado, se dilata o se condensa en función de la experiencia del personaje y de cómo relate su vida y se la explique. Además, esta no es la única manera en que se manifiesta, dado que los múltiples personajes en ocasiones reflexionan sobre el tiempo, hablan de él, de cómo lo experimentan; por tanto, se liga a su vivencia psicológica desde el momento en que lo sienten alargarse, retardarse o hacerse interminable.

El análisis de Deseos, sin embargo, no se agota aquí, pues la obra se revela construida mediante una elaborada planificación estructural cuyo centro es la temporalidad. Así, se puede conceder una significación funcional al tiempo, puesto que cohesiona la realidad de la novela y resuelve los problemas de 
unidad, originados por la abundancia de personajes, y de la simultaneidad enmarcando las distintas voces en diversas horas del día. Además, a través de las indicaciones temporales tanto implícitas como explícitas, se colabora a organizar la materia narrativa a la vez que se encauza una ruta de sucesión de los acontecimientos que guía el imaginario del lector. Siguiendo en el plano retórico, una vez estudiados los tipos de analepsis que pueden hallarse en la novela -es decir, las externas, las internas y las mixtas- se descifra el carácter ineludible de estas para la construcción del discurso en Deseos, y lleva a preguntarse ¿por qué esa proliferación de retrospecciones? O llevándolo a un plano ontológico, ¿por qué esa insistencia de los personajes por organizar su vida, por desmentirse, por crearse un sumario? Estos interrogantes asaltan dado que las analepsis no solo remiten a un plano retórico, estrictamente textual, sino que en esta novela responden a las constantes introspecciones de los personajes, quienes parecen impelidos a revisar su biografía para hallar la raíz de sus deseos. Y es precisamente por esas incursiones de los personajes en sí mismos, que los llevan a revisar su pasado, por lo que puede hablarse de tiempos, el de cada uno y, en definitiva, la manera subjetiva de vivirlo y sentirlo.

\section{Bibliografía}

1. Bajtin, M. (1991). Las formas del tiempo y del cronotopo en la novela. In Bajtin, M., Teoría y estética de la novela (pp. 237- 409). Madrid: Taurus.

2. Baquero Goyanes, M. (1970). Espacio y tiempo. Estructura y ritmo. In Estructuras de la novela actual (pp. 77-85). Barcelona: Planeta.

3. Bergson, H. (1991). Assaig sobre les dades immediates de la consciència. La intü̈ció filosòfica. Barcelona: Edicions 62.

4. Bergson, H. (2012). Memoria y vida. Madrid: Alianza.

5. Bergson, H. (2012). Segunda lección: el tiempo. In Bergson, H., Lecciones de estética y metafísica (pp. 98-105). Madrid: Siruela.

6. Bobes Naves, M.C. (1985). Las unidades sintácticas: el tiempo. In Bobes Naves, M.C., Teoría general de la novela. Semiología de "La Regenta" (pp. 147-195). Madrid: Gredos.

7. Borges, J.L. (2003). El Aleph. In Borges, J.L., El Aleph (pp. 175-198). Madrid: Alianza.

8. Cortázar, J. (2012). La autopista del sur. In Cortázar, J., Todos los fuegos el fuego (pp. 11-49). Barcelona: Edhasa.

9. Ducrot, O. \& Todorov, T. (1981). Tiempo del discurso. In Ducrot, O. \& Todorov, T., Diccionario enciclopédico de las ciencias del lenguaje (pp. 357-363). Madrid: Siglo XXI. 
10. Garrido Domínguez, A. (1993). El tiempo narrativo. In Garrido Domínguez, A., El texto narrativo (pp. 157-206). Madrid: Síntesis.

11. Genette, G. (1989). Figuras III. Barcelona: Lumen.

12. Heidegger, M. (2012). Ser y tiempo. Madrid: Trotta.

13. Hipona, S.A. de (2007). Llibreonzè. In Hipona, S.A. de, Confessions (pp. 319354). Barcelona: Proa.

14. Iser, W. (1997). La ficcionalización: dimensión antropológica de las ficciones literarias. In Garrido Domínguez, A., Teorías de la ficción literaria (pp. 43-65). Madrid: Arco.

15. Kant, I. (1976). Sección segunda de la estética trascendental. Del tiempo. In Kant, I., Crítica de la razón pura. Estética trascendental y analítica trascendental (vol. I, pp. 183-191). Buenos Aires: Losada.

16. Mayoral, M. (2011). Deseos. Madrid: Alfaguara.

17. Pozuelo Yvancos, J.M. (1992). Tiempo y relato. In Pozuelo Yvancos, J.M., Teoría del lenguaje literario (pp. 260-266). Madrid: Cátedra.

18. Pozuelo Yvancos, J.M. (2004). Tiempo del relato y representación de la subjetividad (Un problema teórico en unos cuentos de Julio Cortázar). In Pozuelo Yvancos, J.M., Ventanas de la ficción. Narrativa hispánica, siglos XX y XXI (pp. 92-108). Barcelona: Península.

19. Ricoeur, P. (1987). Tiempo y narración. II Configuración del tiempo en el relato de ficción. Madrid: Ediciones Cristiandad.

20. Ricoeur, P. (1996). Tiempo y narración III. El tiempo narrado. Madrid: Siglo XXI.

21. Sanz Villanueva, S. \& Barbachano, C. (1976). De la innovación al experimento en la novela actual. In Sanz Villanueva, S. \& Barbachano, C. (eds.), Teoría de la novela (pp. 229-264). Madrid: Sociedad General Española de Librería.

22. Villanueva, D. (1977). La estructura de la novela. In Villanueva, D., Estructura y tiempo reducido en la novela (pp. 9-41). Valencia: Bello.

23. Villanueva, D. (1977). La renovación de la novela en el S. XX. In Villanueva, D., Estructura y tiempo reducido en la novela (pp. 42-76). Valencia: Bello.

\section{Author's Biodata}

Christian Snoey Abadias. Graduado en Lengua y Literatura Hispánicas por la Universitat Rovira i Virgili con una media de excelente (promoción 2009-2013). Ha sido becario de colaboración en el Departament de Filologies Romàniques durante el curso 2012-2013, tutelado por el Dr. Manuel Fuentes. En el marco de ese proyecto de investigación presentó una ponencia acerca de la narrativa de Martín Caparrós en el XXXV Convegno Internazionale di Americanistica de Salerno. 
